\title{
Differential Scanning Calorimetry, NBO and Hyperpolarizability Analysis of Yohimbine Hydrochloride
}

\author{
Bhawani Datt Joshi' ${ }^{1,2}$, Poonam Tandon ${ }^{1}$ and Sudha Jain ${ }^{3}$ \\ ${ }^{1}$ Department of Physics, University of Lucknow, Lucknow-226007, India. \\ ${ }^{2}$ Department of Physics, Siddhanath Sc. Campus, Mahendranagar, Tribhuvan Univ, Nepal. \\ ${ }^{3}$ Department of Chemistry, University of Lucknow, Lucknow-226007, India. \\ Correspondence: bdjoshi_007@yahoo.com
}

\begin{abstract}
Yohimbine $\left(\mathrm{C}_{21} \mathrm{H}_{27} \mathrm{~N}_{2} \mathrm{O}_{3}\right)$ is one of the most important indole alkaloid. Differential scanning calorimetry, natural bond orbital (NBO) analysis and dipole moment with hyperpolarizability have been performed for molecular characterization. Stability of the molecule arising from hyper conjugative interactions, charge delocalization has been analyzed using NBO analysis. The results show that charge in electron density (ED) in the $\sigma^{*}$ and $\pi^{*}$ anti bonding orbitals and E(2) energies confirms the occurrence of intra molecular charge transfer (ICT) within the molecule.
\end{abstract}

Keywords: $Y H C l, D S C, N B O$, Hyperpolarizability.

\section{Introduction}

Indole alkaloid group, the naturally-occurring heterocylic amines derived from botanical sources, has received more chemical attention during the last decade. They have been recoized for their great medical value. Yohimbine, found in the stem bark of tall evergreen tree Pausinystilia yohimbe, which grows in tropical West Africa and Congo, also in the roots of Rauwolfia serpentina, is one of most reputed indole alkaloid (Ambadey et al., 1973; van Tamelen et al., 1969; Quinton, 1963). Among many other extracts, yohimbine hydrochloride ( $\mathrm{YHCl}$ ) is a Food and Drug Administration (FDA) approved prescription drug for the treatment of impotence (Betz et al., 1995). It has been used since ancient time for its potent aphrodisiac property (Ambadey et al., 1973; van Tamelen et al., 1969; Quinton, 1963; Eweka et al., 2010], and has been used even in the crude form by African natives. It is promoted for erectile dysfunction, weight loss and depression (Goldberg and Robertson, 1983; Tank et al., 2007). Yohimbine has also been used in traditional medicine to treat high blood pressure, chest pain, agerelated cognitive disorders and obesity (YohimbineSupplement Review, 2010). The optimized structure of $\mathrm{YHCl}$ is given in Fig. 1, below.

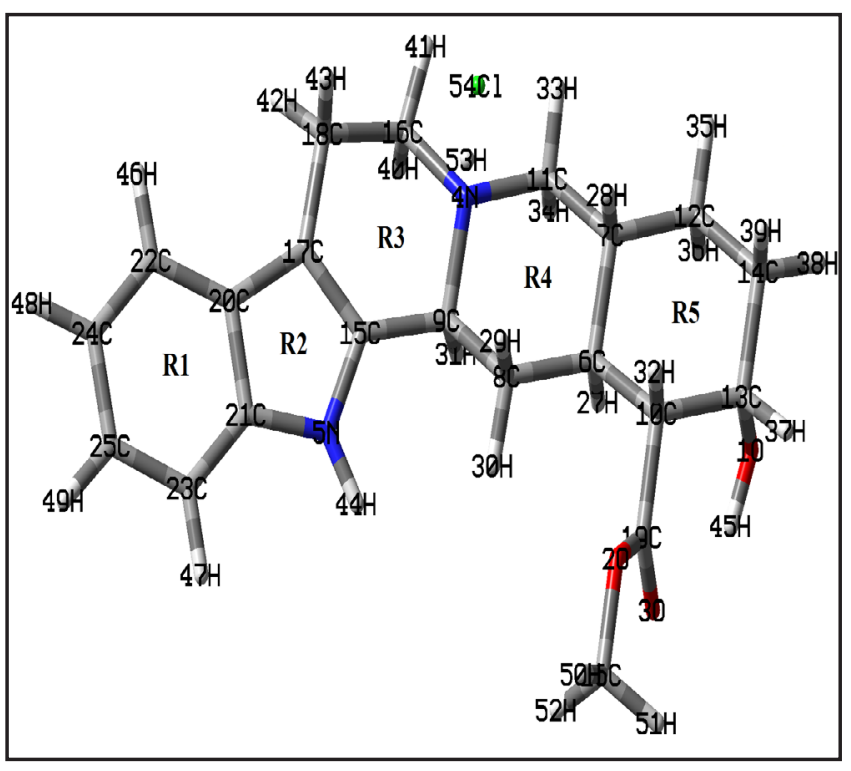

Fig. 1. Optimized structure of $\mathrm{YHCl}$.

Recently, we have observed the experimental IR, Raman (noble tools of vibrational spectroscopy) and UV-vis spectra of the title molecule and analysed a comparison to their theoretical calculations with full potential energy distribution (PED) analysis (Joshi et al., 2011). In this communication we have given natural bond orbital (NBO) analysis, static dipole moment, polarizability by density functional theory (DFT) and differential scanning calorimetry (DSC). NBO 
analysis elucidates the charge delocalization within the molecule. DSC analysis, a thermal experimental technique, helps to know the purity as well as the transition temperatures (like glass transition, melting, boiling, decomposition etc). We have used DSC to find the melting point of $\mathrm{YHCl}$.

\section{Methodology}

\section{Experimental}

The $\mathrm{YHCl}$ in powder form was extracted from Rauwolfia serpentine Benth. (Apocynaceae) by acid base extraction method and purified by a combination of column and preparative thin layer chromatography, converted to its hydrochloride, crystallized from methanol-ether, m. p. $299.5^{\circ}$ [301 ${ }^{\circ}$ (Warnat, 1930; Swan, 1950). The compound was identified as yohimbine by a direct comparison with an authentic sample procured from Sigma Chemical Company, USA.

Differential scanning calorimetry (DSC) analysis was performed using a Mettler Toledo 821 ${ }^{\mathrm{e}}$ DSC (Mettler Toledo, Switzerland) operating with version 5.1 of Stare software. The sample (3.04 mg) was encapsulated in aluminium pan having pierced lids to allow escape of volatiles. The heating rates of $10{ }^{\circ} \mathrm{C} \mathrm{min}{ }^{-1}$ and nitrogen purge at $30 \mathrm{ml} \mathrm{min}{ }^{-1}$ were employed. The temperature axis and the cell constant were calibrated using indium.

\section{Computational}

NBO analysis and the polarizability properties of the molecule were computed by the DFT method using the Gaussian 09 program (Frisch et al., 2009) package at Becke's three parameter (local, nonlocal, Hartree-Fock) hybrid exchange functional with LeeYang-Parr correlation functional (B3LYP) (Lee et al., 1998; Becke, 1993; Parr and Yang, 1989) employing $6-311++\mathrm{G}(\mathrm{d}, \mathrm{p})$ basis set. The basis set 6-311++G(d,p) augmented by ' $d$ ' polarization functions on heavy atoms and ' $p$ ' polarization functions on hydrogen atoms as well as diffuse functions for both hydrogen and heavy atoms. All the donor and acceptor occupancies with their interaction energies were reported with the help of obtained second-order micro pertutbation theory.

\section{Results and discussions \\ Differential Sccaning Calorimety (DSC)}

Differential scanning calorimetry (DSC), is a fundamental tool in thermal analysis, has been widely used as an experimental technique for the study of a variety of phase transformations (Vazquez et al., 1996; Borrego and Gonzalez-Doncel, 1998; Vazquez, 1997). It can be used in many industries - from pharmaceuticals to polymers and from nanomaterials to food products. The information these instruments generate is used to understand amorphous and crystalline behavior, polymorph and eutectic transitions, curing and degree of cure, and many other material properties used to design, manufacture and test products.

DSC analysis showed an endothermic peak for $\mathrm{YHCl}$. The melting endothermic during heating was occurred at $297.87{ }^{\circ} \mathrm{C}$ (onset-peak-endset) with enthalpy of $270.18 \mathrm{~J} / \mathrm{g}$, while during cooling an exothermic peak was occurred at $249.98{ }^{\circ} \mathrm{C}$ with enthalpy of 90.47 $\mathrm{J} / \mathrm{g}$ (Fig. 2). From the curve it is clear that no glass transition has occurred so far.

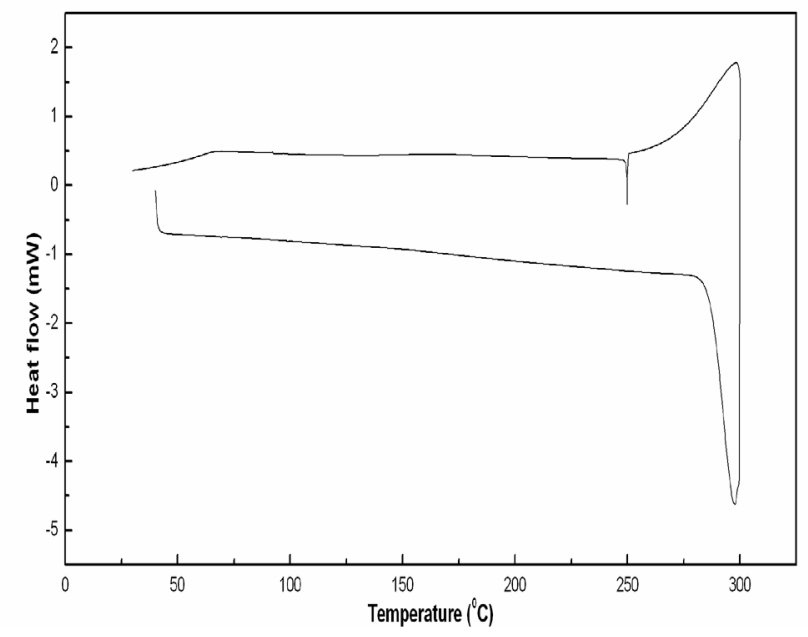

Fig. 2. DSC curve of $\mathrm{YHCl}$ for a heating rate $10{ }^{\circ} \mathrm{C} / \mathrm{min}$ in N2 atmosphere.

\section{Natural Bond Orbital (NBO) analysis}

NBO analysis is based on a method for electronic structure description like as the classic Lewis bonding theory (Weinhold and Landis, 2005, 2001; Reed et al., 1988). It provides a convenient basis for investigating charge transfer or conjugative interaction in molecular systems, which enhance the analysis of intra- and 
intermolecular charge interaction between the localized NBO and empty molecular bonds. Using the secondorder micro disturbance theory, we have reported the occupancy of the filled NBOs (bonds, lone pairs) and the empty NBOs (antibonds, Rydbegs), as well as their interaction energies (James et al., 2006; Na et al., 2005). The electron delocalization from filled NBOs (donors) to the empty NBOs (acceptors) describes as a conjugative electron transfer process between them. Higher the stabilization energy E(2), more intense is the bond interaction. For each donor $(i)$ and acceptor $(j)$, the stabilization energy $\mathrm{E}(2)$ associated with the delocalization $i \rightarrow j$ is estimated as (Weinhold and Landis, 2005, 2001):

$\mathrm{E}(2)=-n_{\sigma} \frac{\langle\sigma|F| \sigma\rangle^{2}}{\varepsilon_{\sigma} *-\varepsilon_{\sigma}}=-n_{\sigma} \frac{F_{i j}{ }^{2}}{\Delta \mathrm{E}}$

where $(<\sigma|F| \sigma\rangle)^{2}<\sigma|\mathrm{F}| \sigma>^{2}$ or $F_{i j}{ }^{2} \quad \mathrm{~F}_{i j}{ }^{2}$ is the Fock matrix element which corresponds to $i$ and $j$ NBO orbitals. $\mathrm{n}_{\sigma}$ is the population of the donar $\sigma$ orbital, $\varepsilon_{\sigma^{*}}$ $\& \varepsilon_{\sigma}$ are the energies of $\sigma^{*} \& \sigma$ NBOs.

Lower occupancy (i.e., electron density) of bonding NBO means more electrons have been donated into antibonding NBOs (Bing et al., 2008), thus lower occupancy leads to stronger donor-ability. From Table 1, it can be seen that the values of occupancy are 1.96053-1.99349 and 1.72711-1.98400 for $\sigma$ and $\pi$ bonding NBOs respectively. Therefore, $\pi$ bonding NBOs possesses higher donor-ability than $\sigma$ bonding NBOs. The $\pi$ bonding NBO at $\mathrm{C} 22$ - C24 has lowest occupancy 1.72711, hence posses the strongest donor ability among all the bonding NBOs. Similarly, larger occupiencies of the antibonding NBOs leads to the stronger acceptor ability. As to the parameters of antibonding NBOs shown in Table 1, the occupancies of $\pi^{*}$ NBOs are much larger than those of $\sigma^{*}$ NBOs and hence have stronger acceptor ability.
Table 1. Selected second order perturbation theory analysis of Fock matrix in $\mathrm{NBO}$ basis of $\mathrm{YHCl}$.

\begin{tabular}{|c|c|c|c|c|c|c|}
\hline Donor NBO & ED (i)/e & Acceptor NBO & $E D(j) / e$ & $\begin{array}{l}\mathrm{E}(2) \\
\mathrm{a}^{\quad \mathrm{kJ}} \\
\mathrm{mol}^{-1}\end{array}$ & $\begin{array}{l}E(j)- \\
E(i)^{b} \\
\text { a.u. }\end{array}$ & \\
\hline $\mathrm{LP}(2) \mathrm{O} 1$ & 1.96001 & $\sigma^{*} \mathrm{C} 13-\mathrm{C} 14$ & 0.03307 & 30.01 & 0.67 & 0.062 \\
\hline LP (1) $\mathrm{O} 2$ & 1.96438 & $\sigma^{*} \mathrm{O} 3-\mathrm{C} 19$ & 0.02195 & 33.57 & 1.12 & 0.085 \\
\hline \multirow[t]{3}{*}{$\mathrm{LP}(2) \mathrm{O} 2$} & 1.78826 & $\pi^{*} \mathrm{O} 3-\mathrm{C} 19$ & 0.22692 & 220.70 & 0.31 & 0.115 \\
\hline & & $\sigma^{*} \mathrm{C} 26-\mathrm{H} 51$ & 0.01353 & 17.97 & 0.76 & 0.054 \\
\hline & & $\sigma^{*} \mathrm{C} 26-\mathrm{H} 52$ & 0.01386 & 18.22 & 0.76 & 0.054 \\
\hline \multirow[t]{2}{*}{ LP(2) O3 } & 1.84742 & $\sigma^{*} \mathrm{O} 2-\mathrm{C} 19$ & 0.10495 & 149.77 & 0.60 & 0.133 \\
\hline & & $\sigma^{*} \mathrm{C} 10-\mathrm{C} 19$ & 0.06508 & 79.88 & 0.64 & 0.101 \\
\hline LP(1)Cl 54 & 1.99921 & $\sigma^{*} \mathrm{~N} 4-\mathrm{H} 53$ & 0.23404 & 33.86 & 1.02 & 0.086 \\
\hline $\mathrm{LP}(4) \mathrm{Cl} 54$ & 1.76221 & $\sigma^{*} \mathrm{~N} 4-\mathrm{H} 53$ & 0.23404 & 377.37 & 0.56 & 0.201 \\
\hline \multirow[t]{2}{*}{ бN5 - C15 } & 1.98211 & $\sigma^{*} \mathrm{C} 21-\mathrm{C} 23$ & 0.02205 & 17.31 & 1.39 & 0.068 \\
\hline & & $\sigma^{*} \mathrm{C} 9-\mathrm{C} 15$ & 0.02798 & 18.27 & 1.22 & 0.065 \\
\hline бC 8 - H30 & 1.97396 & $\sigma^{*} \mathrm{~N} 4-\mathrm{C} 9$ & 0.03944 & 20.65 & 0.75 & 0.054 \\
\hline бC9 - C15 & 1.97443 & $\sigma^{*} \mathrm{C} 15-\mathrm{C} 17$ & 0.02234 & 18.35 & 1.29 & 0.067 \\
\hline бC9 - H31 & 1.96971 & $\pi^{*} \mathrm{C} 15-\mathrm{C} 17$ & 0.31644 & 17.31 & 0.57 & 0.047 \\
\hline бC10 - H32 & 1.95883 & $\pi^{*} \mathrm{O} 3-\mathrm{C} 19$ & 0.22692 & 18.73 & 0.49 & 0.044 \\
\hline$\sigma \mathrm{C} 15-\mathrm{C} 17$ & 1.96638 & $\sigma^{*} \mathrm{C} 20-\mathrm{C} 22$ & 0.02352 & 19.35 & 1.29 & 0.069 \\
\hline \multirow[t]{2}{*}{$\sigma \mathrm{C} 17-\mathrm{C} 20$} & 1.96477 & $\sigma^{*} \mathrm{C} 9-\mathrm{C} 15$ & 0.02798 & 24.96 & 1.07 & 0.071 \\
\hline & & $\sigma^{*} \mathrm{C} 20-\mathrm{C} 22$ & 0.02352 & 19.45 & 1.23 & 0.068 \\
\hline бC18 - H42 & 1.97136 & $\sigma^{*} \mathrm{~N} 4-\mathrm{C} 16$ & 0.02942 & 19.86 & 0.75 & 0.053 \\
\hline$\sigma \mathrm{C} 18$ - H43 & 1.97121 & $\pi^{*} \mathrm{C} 15-\mathrm{C} 17$ & 0.31644 & 18.60 & 0.53 & 0.047 \\
\hline \multirow[t]{2}{*}{$\sigma \mathrm{C} 20-\mathrm{C} 21$} & 1.96053 & $\sigma^{*} \mathrm{C} 17-\mathrm{C} 18$ & 0.02256 & 21.03 & 1.09 & 0.066 \\
\hline & & $\sigma^{*} \mathrm{C} 21-\mathrm{C} 23$ & 0.02205 & 18.56 & 1.24 & 0.067 \\
\hline \multirow[t]{2}{*}{$\sigma \mathrm{C} 20$ - C22 } & 1.97389 & $\sigma^{*} \mathrm{C} 17-\mathrm{C} 20$ & 0.02869 & 21.74 & 1.23 & 0.071 \\
\hline & & $\sigma^{*} \mathrm{C} 20-\mathrm{C} 21$ & 0.02807 & 16.80 & 1.23 & 0.063 \\
\hline$\sigma \mathrm{C} 21-\mathrm{C} 23$ & 1.97560 & $\sigma^{*} \mathrm{C} 20-\mathrm{C} 21$ & 0.02807 & 19.81 & 1.25 & 0.069 \\
\hline$\sigma \mathrm{C} 22-\mathrm{C} 24$ & 1.97856 & $\sigma^{*} \mathrm{C} 17-\mathrm{C} 20$ & 0.02869 & 19.90 & 1.23 & 0.068 \\
\hline$\sigma \mathrm{C} 22$ - H46 & 1.98132 & $\sigma^{*} \mathrm{C} 22-\mathrm{C} 24$ & 0.01453 & 17.56 & 1.06 & 0.060 \\
\hline$\sigma \mathrm{C} 23-\mathrm{C} 25$ & 1.97578 & $\sigma^{*} \mathrm{~N} 5-\mathrm{C} 21$ & 0.02478 & 26.50 & 1.13 & 0.076 \\
\hline$\sigma \mathrm{C} 23-\mathrm{H} 47$ & 1.98103 & $\sigma^{*} \mathrm{C} 20-\mathrm{C} 21$ & 0.02807 & 17.47 & 1.07 & 0.060 \\
\hline$\sigma \mathrm{O} 2$ - C19 & 1.99349 & $\sigma^{*} \mathrm{C} 6-\mathrm{C} 10$ & 0.02477 & 19.98 & 0.03 & 0.043 \\
\hline \multirow[t]{2}{*}{ бN5 - C21 } & 1.98400 & $\pi^{*} \mathrm{C} 15-\mathrm{C} 17$ & 0.31644 & 74.74 & 0.08 & 0.044 \\
\hline & & $\pi^{*} \mathrm{C} 23-\mathrm{C} 25$ & 0.01461 & 365.79 & 0.07 & 0.096 \\
\hline \multirow[t]{2}{*}{$\pi \mathrm{N} 5-\mathrm{C} 21$} & 1.98400 & $\pi^{*} \mathrm{C} 15-\mathrm{C} 17$ & 0.31644 & 89.03 & 0.37 & 0.084 \\
\hline & & $\pi^{*} \mathrm{C} 23-\mathrm{C} 25$ & 0.33007 & 22.70 & 0.37 & 0.042 \\
\hline$\pi \mathrm{C} 15-\mathrm{C} 17$ & 1.96638 & $\pi^{*} \mathrm{~N} 5-\mathrm{C} 21$ & 0.79516 & 27.84 & 0.23 & 0.042 \\
\hline$\pi \mathrm{C} 22-\mathrm{C} 24$ & 1.72711 & $\pi^{*} \mathrm{C} 23-\mathrm{C} 25$ & 0.33007 & 84.10 & 0.28 & 0.067 \\
\hline \multirow[t]{2}{*}{$\pi \mathrm{C} 23-\mathrm{C} 25$} & 1.73199 & $\pi^{*} \mathrm{C} 5-\mathrm{C} 21$ & 0.79516 & 145.13 & 0.21 & 0.088 \\
\hline & & $\pi^{*} \mathrm{C} 22-\mathrm{C} 24$ & 0.30730 & 73.69 & 0.29 & 0.064 \\
\hline
\end{tabular}

${ }^{a} E(2)$ means energy of hyper conjugative interaction (stabilization energy). ${ }^{b}$ Energy difference between donor and acceptor $i$ and $j$ NBO orbitals. ${ }^{\mathrm{c}} F(i, j)$ is the Fock matrix element between $i$ and $j \mathrm{NBO}$ orbit als.

The lone pair (LP) to the anti-bonding acceptor interactions, related to the resonance in the molecule, are electron delocalization from $\mathrm{O} 2$ atom as $\mathrm{LP}(2) \rightarrow$ $\pi^{*}\left(\mathrm{O} 3\right.$ - C19) of carbonyl group and $\mathrm{LP}(2) \rightarrow \sigma^{*}(\mathrm{C} 26$ - H51)/LP(2) $\rightarrow \sigma^{*}(\mathrm{C} 26-\mathrm{H} 52)$ of the methyl group. This shows the conjugation between the electron donation group and the acceptors, which correspond 
tothe stabilization energy 220.70 and $\sim 18 \mathrm{~kJ} \mathrm{~mol}^{-1}$, respectively. While the lone pair electron interaction between $\mathrm{Cl} 54$ atom and the antibonding $\sigma^{*}(\mathrm{~N} 4-$ $\mathrm{H} 53$ ) of the ring R3, which leads to the stabilization energy $377.37 \mathrm{~kJ} \mathrm{~mol}^{-1}$. $\sigma(\mathrm{N} 5-\mathrm{C} 21)$ bonding electron conjugated with $\pi^{*}(\mathrm{C} 15-\mathrm{C} 17)$ and $\pi^{*}(\mathrm{C} 23-\mathrm{C} 25)$ result stabilization energy 74.74 and $365.79 \mathrm{~kJ} \mathrm{~mol}^{-1}$, respectively. The electron delocalization from $\pi(\mathrm{C} 23$ - C25) to antibonding $\pi^{*}(\mathrm{C} 5-\mathrm{C} 21)$ and $\pi^{*}(\mathrm{C} 22-$ $\mathrm{C} 24)$ in the ring R1 leads to the stabilization energy 145.13 and $73.69 \mathrm{~kJ} \mathrm{~mol}^{-1}$, respectively. These various interactions between the filled NBOs and empty NBOs show the intramolecular charge transfer (ICT) in the molecule.

\section{Dipole Moment, Mean Polarizability and First Hyperpolarisability}

The first hyperpolarizability $\left(\beta_{0}\right)$ and related properties $\left(\beta, \alpha_{0}\right.$ and $\left.\Delta \alpha\right)$ of this novel molecular system, $\mathrm{YHCl}$ were calculated, based on the finite-field approach, following the B3LPY level of theory employing $6-311++G(d, p)$ basis set. In the presence of an applied electric field, the energy of a system is a function of the electric field also. First hyperpolarizability is a third rank tensor of order three that can be described by a $3 \times 3 \times 3$ matrix. The 27 components of the $3 \mathrm{D}$ matrix can be reduced to 10 components using the Kleinman Symmetry (Kleinman, 1962) and it can be given in the lower tetrahedral format. It is obvious that the lower part of the $3 \times 3 \times 3$ matrix is a tetrahedral. The components of $\beta$ are defined as the coefficients in a Taylor series expansion of the energy in the external electric field. When the external electric field is weak and homogeneous, the expansion of the energy in the external electric field can be written as:

$$
\mathrm{E}=\mathrm{E}^{0}-\mu_{\alpha} \mathrm{F}_{\alpha}-1 / 2 \alpha_{\alpha \beta} \mathrm{F}_{\alpha} \mathrm{F}_{\beta}-1 / 6 \beta_{\alpha \beta \gamma} \mathrm{F}_{\alpha} \mathrm{F}_{\beta} \mathrm{F}_{\gamma}+\ldots
$$

where $\mathrm{E}^{0}$ is the energy of the unperturbed molecules, $\mathrm{F}_{\alpha}$ is the field at the origin and $\mu_{\alpha,} \alpha_{\alpha \beta}$, and $\beta_{\alpha \beta \gamma}$ are the components of dipole moment, polarizabilities, and the first hyperpolarizabilities, respectively. The polarizability $\alpha$ and the hyperpolarizability $\beta$ are the second and third rank tensors, respectively (Karna et al., 1991). The total static dipole moment $\mu$, the mean polarizability $\alpha_{0}$, the anisotropy of the polarizability $\Delta \alpha$, and the first hyperpolarizability $\beta_{0}$ are defined as follows using the $\mathrm{x}, \mathrm{y}, \mathrm{z}$ components:

$$
\begin{aligned}
& \mu=\left(\mu_{\mathrm{x}}^{2}+\mu_{\mathrm{y}}^{2}+\mu_{\mathrm{z}}^{2}\right)^{1 / 2} \\
& \alpha_{0}=1 / 3\left(\alpha_{\mathrm{xx}}+\alpha_{\mathrm{yy}}+\alpha_{\mathrm{zz}}\right) \\
& \Delta \alpha=2^{-1 / 2}\left[\left(\alpha_{\mathrm{xx}}-\alpha_{\mathrm{yy}}\right)^{2}+\left(\alpha_{\mathrm{yy}}-\alpha_{\mathrm{zz}}\right)^{2}+\left(\alpha_{\mathrm{zz}}-\alpha_{\mathrm{xx}}\right)^{2}+6 \alpha_{\mathrm{xx}}^{2}\right]^{1 / 2} \\
& \beta_{0}=\left(\beta_{\mathrm{x}}^{2}+\beta_{\mathrm{y}}^{2}+\beta_{\mathrm{z}}^{2}\right)^{1 / 2}
\end{aligned}
$$

Table 2: Total static dipole moment $\mu$ (Debye), mean polarizability $\alpha_{0}\left(\times 10^{-24} \mathrm{esu}\right)$, anisotropy of polarizability $\Delta \alpha\left(\mathrm{x} 10^{-24} \mathrm{esu}\right)$, and the mean first hyperpolarizability $\beta_{0}\left(\mathrm{x} 10^{-30} \mathrm{esu}\right)$ of $\mathrm{YHCl}$.

\begin{tabular}{ll}
\hline Total static dipole moment $\mu \mu_{x}$ & $=-4.7996$ \\
& $\mu_{y}=2.7117$ \\
& $\mu_{z}=-6.4919$ \\
& $\mu=8.5167$ \\
\hline Mean polarizability $\alpha_{0}\left(\mathrm{x} 10^{-24} \mathrm{esu}\right)$ & $\alpha_{\mathrm{xx}}=-140.881$ \\
& $\alpha_{\mathrm{xy}}=0.2225$ \\
& $\alpha_{\mathrm{yy}}=-161.7081$ \\
& $\alpha_{\mathrm{xz}}=-7.5197$ \\
& $\alpha_{\mathrm{yz}}=26.7223$ \\
& $\alpha_{\mathrm{zz}}=-189.0896$ \\
& $\alpha_{0}=-163.8927 \times 10^{-24}$ \\
\hline
\end{tabular}

Anisotropy of polarizability $\Delta \alpha \Delta \alpha=247.45229 \times 10^{-24}$ (x10-24 esu)

Mean first hyperpolarizability $\beta_{0} \beta_{x x x}=-195.1511$

$\left(\mathrm{x} 10^{-30} \mathrm{esu}\right)$

$\beta_{\text {xyy }}=-38.5857$

$\beta_{x z z}=-50.2414$

$\beta_{\mathrm{yyy}}=107.9132$

$\beta_{x x y}=18.6593$

$\beta_{\mathrm{yzz}}=41.4066$

$\beta_{\text {zzz }}=-52.4277$

$\beta_{\mathrm{xxz}}=11.3243$

$\beta_{\mathrm{yyz}}=-40.8924$

$\beta_{\mathrm{xyz}}=-0.5263$

$\beta_{0}=1692.4090 \times 10^{-30}$

And, $\beta_{x}=\beta_{x x x}+\beta_{x y y}+\beta_{x z z}$

$$
\begin{gathered}
\beta_{y}=\beta_{y y y}+\beta_{x x y}+\beta_{y z z} \\
\beta_{z}=\beta_{z z z}+\beta_{x x z}+\beta_{y y z}
\end{gathered}
$$

The calculated values of the total static dipole moment $\mu$, the mean polarizability $\alpha_{0}$, the anisotropy of the polarizability $\Delta \alpha$, and the mean first hyperpolarizability $\beta_{0}$ of $\mathrm{YHCl}$ are given in Table 2.

\section{Conclusion}

The title molecule has a sharp melting point at 297.87 ${ }^{0} \mathrm{C}$, but no any glass transition has been observed. No 
polymorphic change was observed within the melting. Based on a combined study of DFT with NBO method, a detailed bonding analysis on the title molecule is performed. NBO analysis result reflects the charge transfer within the molecule. Mostly the antibonding $\pi$ NBOs of the indole part posses higher acceptor-ability, while the bonding $\pi$ NBOs have stronger donorability.

\section{Acknowledgement}

Thanks are to the University Grants Commission, Nepal for providing partial financial assistance.

\section{References}

Ambadey, G., and Karth G., 1973. Crystal structure and absolute configuration of yohimbine hydrochloride, C21H27N2O3. J Cryst Mol Struct 3: 37-45.

Becke,A.D.,1993.Density-functionalthermochemistry. III. The role of exact exchange. $J$ Chem Phys 98: 5648-5652.

Betz, J. M., White, K. D. and Der Marderosian, A. H. 1995. Gas chromatographic determina- tion of yohimbine in commercial yohimbe products. J AOAC Int 78(5): 1189-1194.

Bing, Y., Guo, W., Niya, S., and Yuanhe H., 2008. Bonding analysis and stability on alternant B16N16 cage and its dimers. $J$ Mol Model 14:789-795.

Borrego, A., and Gonzalez-Doncel G., 1998.

Calorimetric study of 6061-Al-15 vol.\% $\mathrm{SiC}_{\mathrm{w}}$ PM composites extruded at different temperatures. Mater Sci Eng A 245: 10-18.

Eweka, A. O., Om'Iniabohs, F.A.E., and Momodu O., 2010. The histological effects of mixed diet containing Pausinystalia yohimbe ground stem bark on the kidney of adult Wistar rats (Rattus norvegicus). Biol and Med 2 (1): 30-36.

Frisch, M. J., Trucks, G. W., Schlegel, H. B., Scuseria, G. E., Cheeseman, J. R., Robb, M.

A., Scalmani, G., Barone, V., Mennucci, B., Petersson. G. A., Nakatsuji, H., Caricato, M., Li, X., Hratchian, H. P., Izmzylov, A. F., Bloino, J., Zheng, G., Sonnenberg, J. L., Hada, M., Ehara, M., Toyota, K., Fukuda, R., Ishida, J., Hasegawa, M., Nakajima, T., Honda, Y., Kitao, O., Nakai, H., Vreven, T., Montgomery, J.A., Jr.,
Peralta, J. E., Ogliaro, F., Bearpark, M., Heyd, J. J., Brothers, E., Kudin, K. N., Staroverov, V. N., Kobayashi, R., Normand, J., Raghavachari, A., Rendell, A., Burant, J. C., Iyengar, S. S., Tomasi, J., Cossi, M., Rega, N., Millan, J. M., Klene, M., Knox, J. E., Cross, J. B., Bakken, V., Adamo, C., Jaramillo, J., Gomperts, R., Stratmann, R. E., Yazyev, O., Austin, A. J., Cammi, R., Pomelli, C., Ochterski, J. W., Martin, R. L., Morokuma, K., Zakrzewski, V. G., Voth, G. A., Salvador, P., Dannerberg, J. J., Dapprich, S., Daniels, A. D., Farkas, J., Foresman, B., Ortiz, J. V., Cioslowski, J., and Fox D. J., (2009) GAUSSIAN 09, Revision, (Gaussian, Inc., Wallingford CT).

Goldberg, M. R., and Robertson D., 1983. Yohimbine: a pharmacological probe for study of the $\alpha-2$ adrenoceptor. Pharmcol Rev 35: 143-180.

James. C., AmalRaj, A., Reghunathan, R., et al. 2006. Structural conformation and vibrational spectroscopic studies of 2,6-bis $(p-N, N-$ dimethyl benzylidene)cyclohexanone using density functional theory. $J$ Raman Spectrosc 37: 1381-1392.

Joshi, B. D., Srivastava, A., Tandon, P., and Jain S., 2011. Molecular structure, vibrational spectra and HOMO, LUMO analysis of yohimbine hydrochloride by density functional

theory and $a b$ initio Hartree-Fock calculations. Spectrochim Acta A 82: 270-278.

Karna, S. P., Prasad, P. N., and Dupuis M., 1991. Nonlinear Optical Properties of p- Nitroaniline: An $a b$ initio Time- Dependent Coupled Perturbed Hartree-Fock Study. J Chem Phys 94: 1171-1181.

Kleinman, D.A., 1962. Nonlinear dielectric polarization in optical media. Phys Rev 126: 1977-1979.

Lee, C. T., Yang, W. T., and Parr R.G., 1998. Development of the Colle-Salvetti correlationenergy formula into a functional of the electron density. Phys Rev B 37: 785-89.

Liu, J. N., Chen, Z. R., and Yuan S. F., 2005. Study on the prediction of visible absorption maxima of azobenzene compounds. J Zhejiang Univ Sci B6: 584-589.

Parr, R. G., and Yang W. T., 1989. Density Functional 
Theory of Atoms and Molecules, Oxford, New York,

Quinton, R. M., 1963. The increase in the toxicity of yohimbine induced by imipramine and other drugs in mice. Brit J Pharmacol 21: 51-66.

Reed, A., E., Curtiss, L. A., and Weinhold F., 1988. Intermolecular interactions from a natural bond orbital, donor-acceptor viewpoint. Chem Rev 88: 899-926.

Swan, G.A., 1950. The constitution of yohimbine and related alkaloids. Part IV. A synthesis of yohimbone. J Chem Soc (ii) 24:1534-1539.

Tank, J., Heusser, K., Diedrich, A., Brychta, R. J., Luft, F. C., and Jordanet J., 2007. Yohimbine attenuates baroreflex mediated bradycardia in human. Hypertension (American Heart Association Inc) 50 (5): 899-903.

van Tamelen, E. E., Shamma, M., Burgstahler, A. W., Wolinsky, J., Tamm, R., and Aldrich P. E., 1969. Total Synthesis of Yohimbine (Organic and Biological Chemistry). J Am Chem Soc : 7315-7333.

Vazquez, J., Villares, P., and Jimenez-Garay R., 1997. A theoretical method for deducing the evolution with time of the fraction crystallized and obtaining the kinetic parameters by

DSC, using non-isothermal techniqoes. $J$ Alloys Compounds 257: 259-65.

Vazquez, J., Wagner, C., Villares, P. and Jimenez-Garay R., 1996. Atheoretical method for determining the crystallized fraction and kinetic parameters by DSC, using non-isothermal techniques. Acta Mater 44: 4807-48013.

Warnat, K., (1930). Über den Schmelzpunkt des reinen Yohimbins (Bemerkung zu der Mitteilung von G. Hahn und W. Schuch). Eur J Inorg Chem 63: 2959-2961. (DOI: 10.1002/ cber.19300631100)

Weinhold, F., and Landis C. R., 2005. Valency and bonding: A Natural Bond Orbital Donor

Acceptor Perspective; Cambridge University Press: New York.

Weinhold, F., and Landis, C., R., 2001. Natural Bond Orbitals and Extensions of Localized

Bonding Concepts. Chem Educ Res Pract Eur 2:91104.

Yohimbine-Supplement Review, August 18, 2010, www.Iron Magazine.com. 